way on the lower part of the cornea; the lens glides out without the slightest tendency to pass up and catch in the upper angle.

Irrigation is a routine. It is worked by an assistant from a large flask fitted with two tubes and a rubber bulb, on McKeown's system ; a slightly curved-not bent-nozzle is employed, but this is never permitted to enter the wound.

If the patient is at all troublesome a Smith's hook is used during iridectomy, expression, and irrigation. While the operation is proceeding it is distinctly.the exception for any instructions to be given to the patient, but quite the rule for a lively conversation on the patient's family history to be carried on in Tamil or Telegu between him and one of the peons.

I was much interested to see the number of cases of excision of the tarsal plate for old standing trachoma, and the success which followed the procedure. In examining slides of the specimens obtained I was struck by the frequency with which I found isolated portions of the lacrymal gland embedded in the tarsal plates.

In the after treatment of intra-ocular operations the instillation of weak silver nitrate drops is a very favourite and apparently valuable practice; the instillation causes no pain whatever.

The method of illumination practised both for operating and for subsequent examination was recently described by Colonel Kirkpatrick in a letter to the British Journal of Ophthalmology. It would be difficult to over-estimate its efficacy.

Two points of treatment are, I think, worthy of note; one is the use of picric acid drops in vesicular conditions of the cornea and another an eye bath of saturated magnesium sulphate in sloughing corneal ulcers.

I was particularly fortunate in seeing a large number of cases of the epidemic keratitis described by Colonel Kirkpatrick in the British Journal of Obhthalmology of January, 1920, and also the methods by which he endeavoured to elucidate and treat this peculiarly interesting condition.

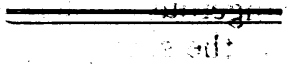

\title{
ANNOTATIONS
}

\section{Trout and Tar Poisoning}

That trout have totally disappeared from a number of English streams since the war is a fact widely known and puzzling, at all events to fishermen. What is the reason? The popular theory until recently has been that it was due to the contamination of the water with tar products from neighbouring roads and by refuse from 
works. To this view a suggestive communication by Messrs. M. S. Mayou and $\mathrm{H}$. Neame dealing with the "late effects of tar poisoning on fish," to be found in another column, furnishes interesting evidence. From a certain Hampshire trout stream, the waters of which had been contaminated from tar used upon the road, fish were taken out in large numbers, dead, dying, and blind. Tar obtained from the road was used for experiments upon fish in ponds, and it was found that the phenol constituents of the tar caused the same effect upon the fish in the pond as upon the fish in the stream. Messrs. Mayou and Neame give a description of the eyes, microscopic and otherwise, of a semi-blinded trout removed from the stream. The question of tar pollution and its effects upon fish is at the present moment under consideration of a joint committee appointed by the Board of Agriculture and Fisheries and the Ministry of Transport. While the foregoing theory has held the field until recently, an attempt has now been made to replace it by another, namely, the multiplication in the streams of pike. A sort of drive was organized over certain reaches of the River Lea, and a surprising number of pike bolted from the weeds. It is possible, then, that this factor, together with the neglect of the rivers which has been general since the war, is a cause of the disappearance of the trout. The statement was made only the other day, however, by a responsible writer in the public Press that " trout have practically disappeared from many a stream where pike do not exist." The writer offered to give instances. But the theory of poisoning by coal-tar effluents (for which there is some good evidence) cannot be dismissed lightly. The presence of pike would doubtless account for the disappearance of trout, but could scarcely be held responsible for the blinding of those fish.

\section{A New Ophthalmological Society}

The inaugural meeting of the South-Western Ophthalmological Society was held on October 22nd last at the Bristol Eye Hospital. The new Society, of which it is hoped to hold about three meetings a year, already numbers fifty members. It is intended to meet the convenience : of the south-western area of England, including Wales, a district that embraces several large towns, notably Bristol, Bath, Cardiff, Plymouth, Cheltenham, and Newport. The first meeting was attended by some thirty members, or three-fifths of the whole, a sign of the excellent spirit that actuates the newcomers, and we trust may continue to do so. About thirty cases were shown and discussed. After lunch at the Grand Hotel, a business meeting was held, when Mr. Richardson Cross was elected president, : Mèssrs; A. C. Roper and R, J. Coulter vice-presidents, 